\title{
SULPHATION OF A CELL SURFACE GLYCOPROTEIN FROM VOLVOX CARTERI
}

\author{
Evidence for a membrane-bound sulfokinase working with PAPS
}

\author{
Peter WILLADSEN and Manfred SUMPER* \\ CSIRO, Division of Animal Nutrition, Long Pocket Laboratories, Private Bag no. 3, Indooroopilly, QLD 4068, Australia and \\ *Universität Regensburg, Fachbereich Biologie und Vorkl. Medizin, Institut für Biochemie, Genetik und Mikrobiologie, \\ 8400 Regensburg, FRG
}

Received 25 January 1982

\section{Introduction}

Sulphated glycoproteins have been implicated in the control of cell growth and differentiation: fibronectins $[1,2]$; glycoproteins in developing sea urchin embryos [3]; and a surface glycoprotein from Volvox carteri [4]. This Volvox glycoprotein, of 185000 app. $M_{\mathrm{r}}$ [4] appears to be involved in the control of the differentiation of the organism during embryogenesis. Although PAPS or APS must be involved as sulphate donor in the synthesis of such molecules, the incorporation of sulphate from PAPS into a sulphated glycoprotein has been demonstrated only in [5]. It was therefore of interest to partially characterize the sulphate-transfer system operative in Volvox.

\section{Materials and methods}

The growth of Volvox carteri $f$. nagariensis female strain HK10, pulse labelling of Volvox in vivo with $\left[{ }^{35} \mathrm{~S}\right]$ sulphate, SDS-polyacrylamide gel electrophoresis on $6 \%$ gels, fluorography and the preparation of Volvox sonicates were as in $[4,6]$. During sonication, gonidia were rapidly destroyed and, although a few somatic cells retained their shape, they were permeable to trypan blue. Membrane and particulate material was isolated by centrifugation of $1 \mathrm{ml}$ samples of sonicate on $4 \mathrm{ml}$ cushions of $20 \%$ sucrose at $110000 \times g$ for $70 \mathrm{~min}$.

Abbreviations: APS, adenosine 5'-phosphosulphate; PAPS, 3'-phosphoadenosine 5'-phosphosulphate

\subsection{Preparation of PAPS and APS}

PAPS was synthesized using the yeast system [7] and isolated by chromatography on DEAE-cellulose, eluting with a linear gradient of $0.15-0.6 \mathrm{M}$ triethylammonium bicarbonate. PAPS was well separated from the adenine nucleotides. Thin-layer chromatography on PEI-cellulose in $0.2 \mathrm{M}$ collidine, $0.1 \mathrm{M}$ acetic acid, $1.2 \mathrm{M} \mathrm{NaCl}$ showed only 2 radioactive components, sulphate and PAPS. Two preparations of $\left[{ }^{35} \mathrm{~S}\right]$ PAPS were used. The first had spec. act. $7.2 \times 10^{9} \mathrm{cpm} / \mu \mathrm{mol}$ and contained $4.6 \%$ free sulphate, while the second had spec. act. $2.0 \times 10^{10} \mathrm{cpm} / \mu \mathrm{mol}$ and $8.3 \%$ free sulphate.

APS was prepared by treatment of PAPS with alkaline phosphatase and identified by chromatography on PEI-cellulose in $0.7 \mathrm{M} \mathrm{LiCl}$ and $0.3 \mathrm{M}$ ammonium bicarbonate, using commercial APS as a standard.

\subsection{In vitro incorporation of inorganic sulphate}

Volvox sonicate was prepared in $400 \mu 10.05 \mathrm{M}$ Tris-acetate buffer containing $10 \mathrm{mM} \mathrm{MgCl}, 10 \mathrm{mM}$ cysteine, $1 \mu \mathrm{M}$ sodium sulphate and $10 \mu \mathrm{M}$ carbonylcyanide $p$-trifluoromethoxyphenylhydrazone, at $\mathrm{pH}$ 8.0. Then $200 \mu \mathrm{Ci}$ carrier-free $\left[{ }^{35} \mathrm{~S}\right]$ sulphate and either $40 \mu 10.1 \mathrm{M} \mathrm{ATP}$ or water were added. After $2 \mathrm{~h}$ at $30^{\circ} \mathrm{C}$, the membrane fraction was centrifuged, suspended in $500 \mu \mathrm{l} 0.05 \mathrm{M}$ Tris buffer ( $\mathrm{pH} \mathrm{8.0)}$ containing $200 \mu \mathrm{g}$ subtilisin and, following digestion for $1 \mathrm{~h}$, the samples were dried, denatured in SDSmercaptoethanol and electrophoresed.

\subsection{In vitro incorporation of sulphate from $P A P S$}

Volvox was sonicated in a $0.05 \mathrm{M}$ Tris-acetate 
buffer containing $0.1 \mathrm{M}$ sucrose, $0.1 \mathrm{M} \mathrm{NaF}, 2 \mathrm{mM}$ EDTA, $1 \mathrm{mM}$ sodium sulphate, $10 \mathrm{mM}$ cysteine at $\mathrm{pH}$ 8.0. Incubations were for $2 \mathrm{~h}$ at $30^{\circ} \mathrm{C}$ with PAPS at $3 \mu \mathrm{M}$. Subtilisin treatment and electrophoresis were performed as above.

\subsection{In vitro synthesis of PAPS by Volvox}

Incubations were in $1 \mathrm{ml}$ Tris-acetate buffer containing $10 \mathrm{mM} \mathrm{MgCl}_{2}$ and $0.1 \mathrm{M}$ sucrose at $\mathrm{pH} 8.0$. Synthesis was initiated by addition of $100 \mu \mathrm{l} 0.1 \mathrm{M}$ ATP and $100 \mu \mathrm{l} 5 \mathrm{mM}$ sodium sulphate, containing ${ }^{35} \mathrm{~S}$ as a tracer. After $1 \mathrm{~h}$ at $30^{\circ} \mathrm{C}$ reaction was stopped by the addition of $3 \mathrm{ml}$ ethanol and PAPS partially purified on DEAE-cellulose. Subsequently, samples were chromatographed on PEI-cellulose as before and the synthesized PAPS counted directly.

\section{Results}

All experiments were performed with synchronized Volvox populations in the 4 cell stage of embryogenesis, at which stage rapid sulphate incorporation into a sulphated surface glycoprotein is observed in vivo [4]. In all experiments, product formation or sulphate incorporation is expressed as 'per $100 \mathrm{ml}$ Volvox', that is, relative to the activity measured in the material isolated from $100 \mathrm{ml}$ Volvox culture suspension containing $\sim 15$ colonies $/ \mathrm{ml}$.

\subsection{In vitro incorporation of inorganic sulphate}

Incubation of Volvox sonicates with inorganic sulphate and ATP led to the incorporation of sulphate into a number of high $\boldsymbol{M}_{\mathrm{r}}$ products, most notably a band of diffuse material with an electrophoretic mobility close to that of the $185000 M_{\mathrm{r}}$ glycoprotein synthesized in vivo. If the material was treated with subtilisin following the labelling experiment, then this glycoprotein was not observed, and instead another band of labelled material was found with a mobility corresponding to the $145000 M_{\mathrm{r}}$ gly copeptide produced by the same treatment of in vivo labelled $185000 M_{\mathrm{r}}$ glycoprotein. Up to $0.05 \mathrm{pmol}$ sulphate was found in this component which will be referred to as the $145 \mathrm{kA}$ component. In the absence of ATP there was no detectable incorporation of sulphate (fig.1). Since subtilisin treatment gave a more identifiable product, this step was used routinely.

\subsection{In vitro transfer of sulphate from $P A P S$ to $145 k A$} Incubation of Volvox sonicates with PAPS led to labelling of the $145 \mathrm{kA}$ component. Incorporation of sulphate by hydrolysis of the added PAPS and subsequent activation of the sulphate can be completely excluded: (i) activation of sulphate is exceedingly unlikely in the presence of fluoride and EDTA and in the absence of ATP and magnesium; (ii) $1 \mathrm{mM}$ ;ulphate was always present in the buffers used. This vould dilute any liberated $\left[{ }^{35} \mathrm{~S}\right]$ sulphate to an Indetectable spccific activity.

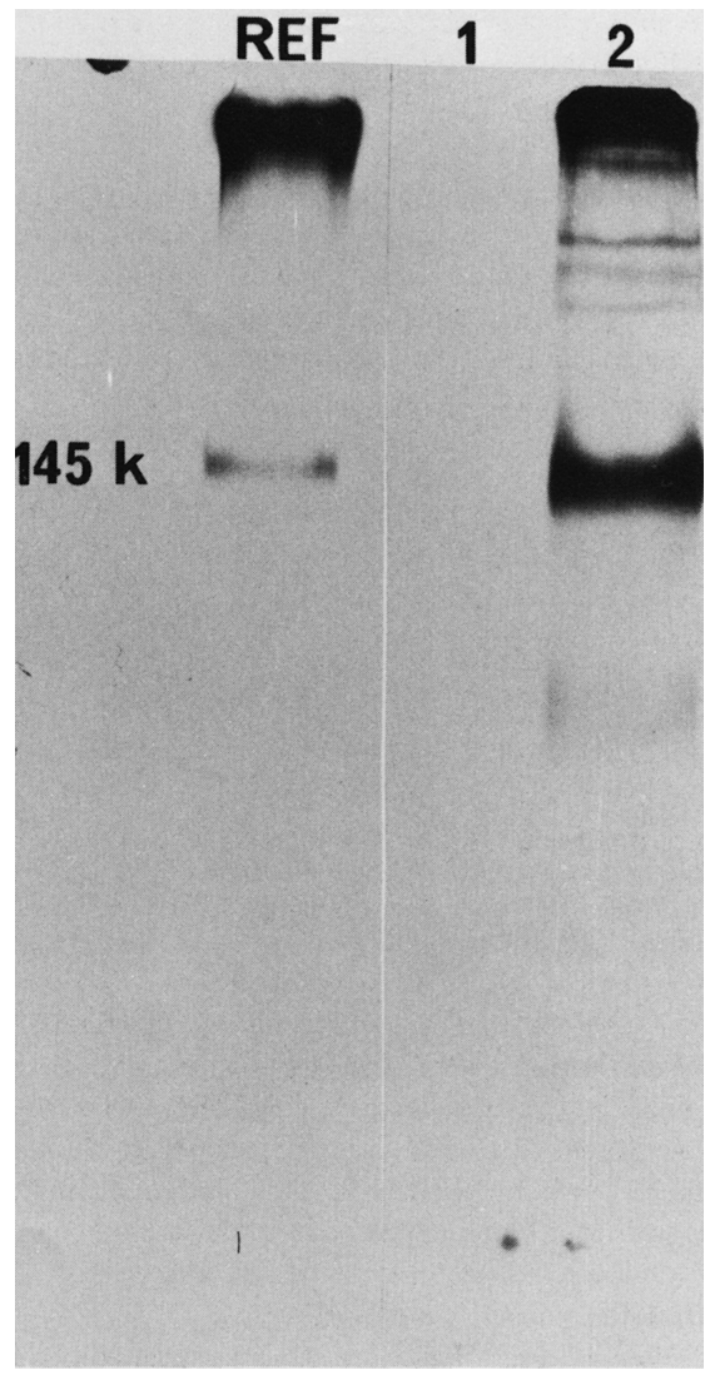

ig.1. SDS-polyacrylamide gel electrophoresis of Volvox nicates mixed with: (1) $\left[{ }^{35} \mathrm{~S}\right]$ sulphate; (2) $\left[{ }^{35} \mathrm{~S}\right]$ sulphate + r. TP. The lane labelled 'Ref' was obtained by in vivo labelling with sulphate and subsequent subtilisin treatment. 
The $145 \mathrm{kA}$ component was frequently more diffuse than the product of in vivo labelling, the $145000 M_{\mathrm{r}}$ gly coconjugate, and it occasionally had a slightly higher electrophoretic mobility. However, the two appear identical ( $145 \mathrm{kA}$ may be a poorly synthesized version of the $145000 M_{\mathrm{r}}$ glycoprotein):

(1) Material with mobility close to that of $185000 M_{\mathrm{I}}$ protein disappears after subtilisin treatment, and $145 \mathrm{kA}$ is produced - this parallels the in vivo results.

(2) $145 \mathrm{kA}$ is the major discrete glycoprotein band which is sulphate labelled in the membrane fraction of Volvox in the 4 cell stage. The same is true for the $145000 M_{\mathrm{r}}$ glycoprotein in vivo.

(3) Treatment of $145000 M_{\mathrm{r}}$ glycoprotein with $1 \mathrm{M} \mathrm{NaOH}$ at $96^{\circ} \mathrm{C}$ for $1 \mathrm{~h}$ produces a single, discrete, sulphate-containing product of $\sim 100000 \mathrm{app} . M_{\mathrm{r}}$. When $145 \mathrm{kA}$ was eluted from gels following electrophoresis and hydrolysed in the same way, a single labelled band of $100000 M_{\mathrm{r}}$ was produced.

Under these conditions, the mean incorporation of sulphate into $145 \mathrm{kA}$ was $0.20 \mathrm{pmol} / 100 \mathrm{ml}$ Volvox (mean of 8 detn., 0.10-0.50 pmol). In in vivo pulse experiments, the mean was $1.4 \mathrm{pmol} / 100 \mathrm{ml}$ Volvox (mean of 7 detn). An accurate comparison of the 2 systems is difficult, since neither is likely to represent optimal incorporation. The in vitro sulphation is, however, not strikingly inefficient, particularly since preliminary results indicate that the in vitro activity is unstable.

\subsection{APS is not an intermediate in the sulphation}

Incubation of Volvox sonicates with $3 \mu \mathrm{M}$ PAPS and $3 \mu \mathrm{M}$ APS in parallel experiments showed the normal incorporation of sulphate from PAPS. None was observed from APS. Thus incorporation from PAPS by preliminary hydrolysis to APS does not occur.

\subsection{Volvox synthesizes PAPS in vivo}

Volvox suspensions were sonicated following normal in vivo pulse labelling with sulphate. PAPS could be identified in the soluble material as in section 2 . The amounts were small: $\leqslant 0.01 \mathrm{pmol}$ PAPS $/ 100 \mathrm{ml}$ Volvox.

\subsection{Transfer of sulphate from PAPS to $145 \mathrm{kA}$ occurs in a particulate system}

Volvox sonicates were separated into membrane and supernatant fractions by centrifugation through $20 \%$ sucrose. These 2 fractions were then retained, and material within the sucrose discarded. Incubations were then made with PAPS and: (i) whole sonicate; (ii) resuspended membrane fraction; (iii) membrane fraction to which was added supernatant, equivalent to that in whole sonicate. Sulphate incorporation in the 3 incubations was, respectively, $0.105,0.107$ and $0.105 \mathrm{pmol} / 100 \mathrm{ml}$ (mean of 2 expt). There is no evidence for the requirement of a soluble sulphokinase (fig.2).

To eliminate the possibility that sulphate incorporation occurred solely on cell ghosts, sonicates were centrifuged sequentially at $500 \times g$ for $10 \mathrm{~min}$, $10000 \times g$ for $20 \mathrm{~min}$ and $110000 \times g$ for $60 \mathrm{~min}$, and the fractions incubated separately with PAPS. Sulphate incorporation into $145 \mathrm{kA}$ occurred almost exclusively in the $500 \times g$ to $10000 \times g$ material.

\subsection{Enzymes synthesizing PAPS in Volvox are partially particle bound}

In view of the above result, it was of interest to

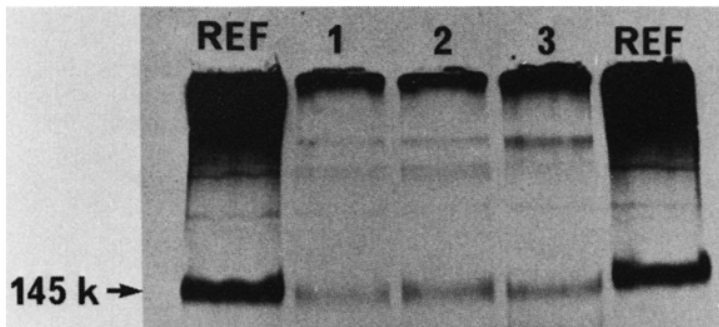

Fig.2. Sulphated proteins following incubation of $\left[{ }^{35} \mathrm{~S}\right] \mathrm{PAPS}$ with: (1) Volvox sonicate; (2) particulate material isolated from the sonicate; (3) recombined particulate and soluble material. The lanes labelled 'Ref' were obtained by in vivo labelling with sulphate and subsequent subtilisin treatment. 
see if the enzymes synthesizing PAPS were also membrane-bound. Therefore whole homogenate, resuspended membrane fraction and supernatant or soluble fraction were incubated with sulphate and ATP as in section 2. Typical net synthesis rates for PAPS were: whole sonicate, $8.9 \mathrm{nmol} / 100 \mathrm{ml}$ Volvox; membrane fraction, $2.2 \mathrm{nmol} / 100 \mathrm{ml}$; supernatant, $3.0 \mathrm{nmol} /$ $100 \mathrm{ml}$. In the absence of added ATP, whole sonicate synthesized $\leqslant 1 \%$ of the above amount of PAPS.

\section{Discussion}

The results demonstrate that sonicates of Volvox incorporate sulphate into high $M_{\mathrm{r}}$ material, including the cell surface glycoprotein which was proposed to be involved in the control of cell differentiation during embryogenesis. The reaction is dependent on ATP. As evidence that PAPS is the sulphate donor, it has been shown that PAPS is synthesized in vivo and in vitro, and that sulphate is transferred in vitro from PAPS to acceptors. Although APS is known to be a sulphate donor in phototrophic bacteria, plants and green algae [7-11], it is not involved here.
The enzyme or enzymes catalyzing the transfer of sulphate from PAPS to protein are particle-bound; synthesis of PAPS seems to be partially particle bound. This suggests that a closely coordinated system incorporates inorganic sulphate into membrane glycoproteins.

\section{References}

[1] Hynes, R. O. (1976) Biochim. Biophys. Acta 458, 73-107.

[2] Dunham, J. S. and Hynes, R. O. (1978) Biochim. Biophys. Acta 506, 242-255.

[3] Heifetz, A. and Lennarz, W. J. (1979) J. Biol. Chem. 254, 6119-6127.

[4] Wenzl, S. and Sumper, M. (1981) Proc. Natl. Acad. Sci. USA 78, 3716-3720.

[5] Miller, R. R. and Waechter, C. J. (1979) Arch. Biochem. Biophys. 198, 31-41.

[6] Starr, R. C. and Jaenicke, L. (1974) Proc. Natl. Acad. Sci. USA 71, 1050-1054.

[7] Robbins, P. W. (1962) Methods Enzymol. 5, 964-977.

[8] Schmidt, A. (1972) Arch. Microbiol. 84, 77-86.

[9] Schmidt, A. (1976) Panta 130, 257-263.

[10] Tsang, M. L. and Schiff, J. A. (1976) Plant Cell Physiol. $17,1209-1220$.

[11] Schmidt, A. (1977) Arch. Microbiol. 112, 263-270. 